\title{
Hypoparathyroidism associated with systemic lupus erythematosus
}

\author{
V. J. HaJirousSOU \\ M.R.C.P.
}

Northampton General Hospital, Northampton

\begin{abstract}
Summary
A case of hypoparathyroidism and systemic lupus erythematosus is reported. It is believed that an association between the 2 diseases has not been described previously.
\end{abstract}

\section{Introduction}

Idiopathic hypoparathyroidism is a rare disease with an obscure aetiology. It is associated with such conditions as Addison's disease, thyroiditis, pernicious anaemia, ovarian failure and moniliasis (Drury et al., 1970). This is believed to be the first reported case of hypoparathyroidism in association with systemic lupus erythematosus (SLE).

\section{Case report}

A 64-year-old Polish catering manager was admitted with increasing shortness of breath, ankle swelling and transient loss of consciousness lasting a few seconds. He had previously been well until 2 months before admission, when he sustained a myocardial infarction. This was complicated by heart failure requiring diuretic therapy. $\mathrm{He}$ was a nonsmoker, drank moderate amounts of alcohol and had a brother suffering from diabetes mellitus.

On examination he was obese, febrile $\left(38^{\circ} \mathrm{C}\right)$ and breathless at rest. $\mathrm{He}$ was normotensive and had clinical signs of heart failure. His liver was enlarged and multiple exudates and a few haemorrhages were seen in both retinae. Trousseau's sign was positive, while Chvostek's sign was negative. The electrocardiogram showed a prolonged QT interval and $T$-wave inversion in the antero-lateral leads. The chest radiograph confirmed the signs of heart failure. The $\mathrm{Hb}$ was $9.8 \mathrm{~g} / \mathrm{dl}$, WCC $5.8 \times 10^{9} / 1$, and the red cells appeared normochromic and normocytic. The ESR was $109 \mathrm{~mm}$ in the first hour. Biochemical profile produced the following results in mmol/l: sodium 138; potassium $3 \cdot 7$; chloride $97 \cdot 5$; bicarbonate 30.7 ; urea 6.6 ; glucose 4.7 ; calcium 0.8 ; phosphate 1.45 ; and albumin $31 \mathrm{~g} / \mathrm{l}$. The urinary calcium was $0.18 \mathrm{mmol} / 24 \mathrm{hr}$ (normal range $2.5-7$ ) and phosphate $5.4 \mathrm{mmol} / 24 \mathrm{hr}$ (normal range 15-50).
Protein electrophoresis showed increased $\alpha_{2}$-globulins and a monoclonal band in the $\gamma$-globulin region. Bence-Jones proteins were not detected in the urine. Immunoglobulins were normal apart from a slightly elevated IgA $(6.05 \mathrm{mmol} / \mathrm{l}$, normal range 0.64-5.4). Bone marrow biopsy was non-contributory and direct Coombs' test was negative. Liver biopsy showed non-specific infiltration of the portal tracts by lymphocytes, and fatty changes in the lobules. Antinuclear antibody was present in the serum in a titre of $1: 1280$. It was unrelated to the monoclonal globulin and had a 'diffuse' pattern on staining. DNA binding was positive to 91 units (normal range $<10$ units). Complement levels were normal. Screening for organ specific antibodies was negative and thyroid function and synacthen tests were normal. Serum parathyroid hormone was undetectable, while the calcium concentration was below the normal range.

Treatment was started with calcium gluconate infusion and continued with $1, \alpha$-hydroxycholecalciferol $(1, \alpha-\mathrm{OHCC})$ and calcium supplements orally. The heart failure responded to diuretics and hydrallazine. During follow-up the patient remained normocalcaemic while on $0.25 \mu \mathrm{g}$ of $1, \alpha-\mathrm{OHCC}$ daily, and calcium supplements. His retinal exudates and haemorrhages disappeared completely. He developed an erythematous rash on the face, a leucopenia (WCC $2.8 \times 10^{9} / 1$ ) and thrombocytopenia (platelets $\left.118 \times 10^{9} / 1\right)$. The ESR and DNA binding remained elevated, while the monoclonal band was no longer detectable.

\section{Discussion}

SLE has been associated with several auto-immune diseases, for example thyroiditis and myasthenia gravis (Garber et al., 1969; Oosterhuis and de Haas, 1968). Such an association with other endocrinopathies, considered to be auto-immune, has not been described. Adrenocortical insufficiency has been reported with SLE, but it is extremely rare and possibly the result of vasculitis (Thiagarajan and Wongsurawat, 1978). 
Idiopathic hypoparathyroidism is suspected of being an auto-immune disease (Davis and Hipkin, 1977). Therefore, as with auto-immune thyroiditis, it may be associated with SLE. Such an association could be based on immunological mechanisms, although ischaemic involvement of the parathyroid glands due to vasculitis cannot be excluded in this patient. Evidence of vasculitis was present in the retinae, where transient exudates and haemorrhages were seen. Whatever the association may be between the 2 diseases, it is unlikely that this case represents a simple co-existence.

The heart failure in this patient may have been secondary to the myocardial ischaemia as shown on the electrocardiogram before and after therapy. In addition, however, his severe hypocalcaemia could have been a significant factor as described by Aryanpur, Farhoudi and Zangeneh (1974) and Brenton, Gonzales and Pollard (1978). Supporting evidence is the relatively small dose of bumetamide (20 mg daily) required to maintain normal exercise tolerance during normocalcaemia. The significance of the transient monoclonal band remains uncertain, although an association with auto-immune diseases has long been recognized (Michaux and Heremans, 1969).

\section{Acknowledgment}

I am grateful to Dr J. S. Birkhead for allowing mecto report his case.

\section{References}

ARyanpur, I., Farhoudi, A. \& Zangeneh, F. (1974) Congestive heart failure secondary to hypoparathyroidiom. American Journal of Diseases of Children, 127, 738.

Brenton, D.P., Gonzales, J. \& Pollard, A.B. (1978) Hyp̧ocalcaemic cardiac failure. Postgraduate Medical Jour $\overrightarrow{\nexists l}$ l. 54, 633.

DAVIS, J.C. \& HIPKIN, L.J. (1977) Clinical Endocrine Pat $\vec{b} \mathrm{l}$ logy, 1st edn, p. 291. Blackwell Scientific Publicati@ors, Oxford.

Drury, M., Keelan, D.M , Timoney, F.J. \& Irvine, J. (1970) Juvenile familial endocrinopathy. Clinical $\underset{\mathrm{mnd}}{\mathrm{H}}$ Experimental Immunology, 7, 125.

GARBER, J.J., WORTHINGTON, J.W., RANDALl, R.V. ơd $^{8}$ KieRLAND, R.R. (1969) Lupus erythematosus and Hasłlimoto's thyroiditis. Postgraduate Medicine, 46, 100.

MichauX, J.L. \& Heremans, J.F. (1969) Thirty casescof monoclonal immunoglobulin disorders other than myelonta or macroglobulinemia. American Journal of Medicine. 46, 562.

OOSTERHUIS, H.J.G.H. \& DE HAAS, W.H.D. (1968) Rhölmatic diseases in patients with myasthenia gravis. A ta neurologica scandinavica, 48, 219.

Thiagarajan, D. \& Wongsurawat, N. (1978) Systemic lupus erythematosus associated with adrenal insufficien⿳亠口冋. Journal of the Kansas Medical Society, 79, 565. 